\title{
Kernos
}

Revue internationale et pluridisciplinaire de religion grecque antique

16 | 2003

Varia

\section{H.F.J. HORSTMANSHOFF et al. (éds), Kykeon. Studies in Honour of H.S. Versnel}

\section{Corinne Bonnet}

\section{(2) OpenEdition \\ Journals}

\section{Édition électronique}

URL : http://journals.openedition.org/kernos/854

DOI : $10.4000 /$ kernos.854

ISSN : 2034-7871

\section{Éditeur}

Centre international d'étude de la religion grecque antique

\section{Édition imprimée}

Date de publication : 1 janvier 2003

Pagination : 384-385

ISSN : 0776-3824

\section{Référence électronique}

Corinne Bonnet, « H.F.J. horstmanshoff et al. (éds), Kykeon. Studies in Honour of H.S. Versnel », Kernos [En ligne], 16 | 2003, mis en ligne le 14 avril 2011, consulté le 24 septembre 2020. URL : http:// journals.openedition.org/kernos/854; DOI : https://doi.org/10.4000/kernos.854 
les implications de ces discours sur la définition des valeurs helléniques et, partant, la spécificité de Pausanias.

Chaque contribution est accompagnée de notes (regroupées en fin de volume) qui exploitent une bibliographie bien fournie (il faut remplacer cependant Aupert P. par Piérart M. comme éditeur de l'ouvrage Éditer, traduire, commenter Pausanias en l'an 2000, paru chez Droz en 2001). Des figures en noir et blanc, un index des passages cités de Pausanias et un index général complètent utilement le tout. Mais la carte de Grèce qui ouvre le volume, sans échelle ni aucune indication de relief, n'est guère suggestive.

Yves Lafond (Université d'Artois)

H.F.J. Horstmanshoff, H.W. Singor, F.T. Van Straten, J.H.M. Strubbe (éds), Kykeon. Studies in Honour of H.S. Versnel, Leiden, Brill, 2002. 1 vol. $16 \times 24,4 \mathrm{~cm}, 228$ p. (Studies in Greek and Roman Religion, 142). ISBN : 90-04-11983-3.

Henk Versnel est une des figures marquantes de l'histoire des religions classiques de notre époque. Devenu émérite en septembre 2000, après avoir enseigné à l'Université de Leiden depuis 1978, il a été honoré par ses collègues par le biais d'un Colloque qui s'est tenu à Leiden en mai 2000, dont les Actes sont intitulés Kykeôn, une « potion magique » en hommage à un des meilleurs connaisseurs du monde de la magie, des rites, des sacrifices, tant sur le versant grec que sur le versant romain ${ }^{1}$. On regrettera du reste que le volume, au demeurant riche et intéressant, ne contienne pas une liste de ses publications.

W. Burkert propose, en Introduction, une mise au point passionnante sur «'Mythos und Ritual' im Wechselwind der Moderne » (p. 1-22). Il met en perspective les recherches sur les rapports entre mythe et rite depuis le début du $\mathrm{xx}^{\mathrm{e}}$ siècle (y compris son fondamental Homo necans paru en 1972) jusqu'à l'époque post-moderne.

A. Chaniotis, en partant des Daidala de Béotie, étudie les « Ritual Dynamics ». Connues par le biais de Plutarque et Pausanias, ces festivités impliquaient directement les rapports entre Héra et Zeus. Le problème est donc de savoir si l'on a affaire à un bieros gamos ou non. En confrontant les diverses analyses, qui insistent tantôt sur le mythe, tantôt sur le rite, l'A. montre bien que la synthèse est à portée de la main, sans forcer la documentation (Putting the pieces togetber), en tenant surtout compte de la stratification chronologique, de «stades » (les Allemands parlent d'Entwicklungsgeschichte) dans le développement du complexe mythico-rituel de Platées. Une telle lecture est susceptible de s'appliquer à bien d'autres fêtes religieuses grecques.

L'essai de B. Gladigow affronte la question de la pluralité culturelle et religieuse de l'Europe, hier comme aujourd'hui, et notamment la manière de concevoir les rapports entre monothéismes et polythéismes, ainsi que l'apport de la koinè religieuse méditerranéenne et de la religion impériale romaine à l'histoire de la religion européenne qui doit être étudiée comme un ensemble, et non pas de manière sectorielle.

R. Gordon, dans la ligne des intérêts scientifiques de Versnel, propose une étude sur les textes magiques gréco-égyptiens. Il y est question du pouvoir magique des noms, de la création de nouvelles techniques, de la manipulation des textes, des images, autant d'éléments destinés à accroître la puissance de l'acte magique. On signalera aux lecteurs une étude récente sur le même sujet, du point de vue socio-linguistique: P. Poccetti, "Manipolazione della realtà e manipolazione della lingua: alcuni aspetti dei testi magici dell'Antichità", in R. Morresi (a cura di), Linguaggio - Linguaggi. Invenzione - Scoperta, Rome, 2002, p. 11-59.

F. Graf répond brillamment à la question «What is new about Greek Sacrifice? », une mise au point synthétique fort intéressante qui tend à confirmer les thèses de Meuli et Burkert sur le sacrifice comme mise à mort de l'animal.

H.J. de Jonge centre son attention sur « The Apocalypse of John and the Imperial Cult », en se rattachant à une étude de Versnel parue en 1988, en rapport avec une publication de F. Millar. La question était de savoir dans quelle mesure le refus de la part

1 Le sommaire de ce livre est présenté infra, p. 392. 
des Chrétiens de pratiquer le culte impérial a déchaîné ou non les persécutions. L'A. se propose d'étudier ici les passages de l'Apocalypse de Jean contraires au culte impérial.

R. Parker étudie, pour sa part, "The Cult of Aphrodite Pandamos and Pontia on Cos », un culte auquel se réfèrent deux longues inscriptions du II $^{\mathrm{e}}$ siècle av. J.C. et qui apparaît aussi dans l'inscription bilingue gréco-phénicienne où Aphrodite est identifiée à Astarté. On trouvera des pages intéressantes sur les rapports entre les deux déesses et sur les éventuelles fonctions marines - fonctions secondaires - d'Astarté.

Le pied de Dionysos est le thème choisi par Renate Schlesier, en tant que symbole de l'épiphanie du dieu, notamment dans un passage de Plutarque. Enfin, c'est encore de Dionysos dont il est question dans l'essai conclusif de F.I. Zeitlin. Apollon et Dionysos sont en effet des demi-frères en tant que fils de Zeus et bien des traits les rapprochent, comme le souligna jadis Nietzsche. Il s'agit ici de comparer les récits relatifs à leur naissance, qui risquent d'être particulièrement lourds de sens lorsque l'on songe à ce que les Grecs entendaient par arcbè, début et raison de toute chose. Comme on pouvait s'y attendre, au-delà des analogies, ce sont les différences qui apparaissent comme particulièrement significatives.

Ce volume d'un très haut niveau, qui fait honneur au grand savant qu'est Versnel, se termine par un index.

Corinne Bonnet

(Université de Toulouse-Le Mirail)

Kenneth D.S. LAPATIN, Cbryselephantine Statuary in the Ancient Mediterranean World, Oxford, University Press, 2001. 1 vol. 22,5×28,5 cm, xvi +242 p., 248 fig. sur planches (Oxford Monographs on Classical Archaeology). ISBN : 0-19-815311-2.

Les statues composites d'or et d'ivoire ont compté parmi les œuvres d'art les plus admirées de l'Antiquité classique. En dépit de leur importance religieuse, artistique et économique, aucune étude d'ensemble ne leur avait été consacrée depuis le Jupiter Olympien de Quatremère de Quincy, paru en 1814. Pour combler cette lacune, l'A. s'est attaché à retracer l'évolution de leur production dans le bassin méditerranéen antique, de l'âge du bronze à l'époque romaine. Son étude repose sur près de 200 sculptures décrites dans les sources littéraires et épigraphiques. Aucune de ces cuvres ne nous est parvenue, mais des copies et des reproductions sur d'autres supports (monnaies, peinture de vase...) nous permettent de nous en faire une idée, même imparfaite. À côté de ces œuvres perdues, l'A. a répertorié plus de 50 objets très fragmentaires, dont aucun texte ne parle, mais qui étaient aussi d'une grande beauté.

Après avoir défini les problèmes posés par la nature lacunaire des sources antiques, il présente les différents types d'ivoire et d'os utilisés (hippopotame, éléphant d'Asie ou d'Afrique, mammouth ...), ainsi que les techniques de travail, de mise en forme et d'assemblage de ce matériau exotique et coûteux. Vraisemblablement, les mêmes artisans ont fabriqué les statues de culte et les objets de plus petite dimension (boîtes, peignes et autres accessoires liés aux soins cosmétiques, ornements de mobilier). Les cuvres sont passées en revue dans l'ordre chronologique, de l'âge du bronze (chap. 3), aux époques orientalisante et archaïque (chap. 4), classique (chap. 5-6), hellénistique et romaine (chap. 7). La principale fonction des sculptures chryséléphantines antiques est religieuse. Son prix élevé, sa rareté et ses qualités mimétiques firent très tôt de l'ivoire le matériau privilégié des statues de divinités. Sa couleur pâle et sa douceur évoquent la luminosité surnaturelle d'une peau divine. Allié à l'or incorruptible, il forme un ensemble précietux dont l'éclat suggère la splendeur des Olympiens. Pour éviter que l'ivoire ne sèche et se fende, des soins spéciaux sont prodigués aux statues (onction d'huile, mise en place à proximité d'un bassin rempli d'eau).

Le travail de l'ivoire, plaqué sur une âme de bois, se développe à l'époque orientalisante. Vers le milieu du $\mathbf{v i}^{\mathbf{e}}$ siècle avant $\mathrm{J}$.-C., les artistes parviennent à réaliser des statues chryséléphantines de taille plus importante, bientôt grandeur nature. Ces produits de luxe manifestent la piété, l'opulence et le pouvoir de ceux qui viennent les dédier dans les grands sanctuaires. L'émulation suscitée par les deux statues colossales de Phidias, l'Athéna Parthénos et le Zeus d'Olympie (dernier quart du ve siècle) perdure jusqu'à l'époque romaine. Les souverains hellénistiques, puis les empereurs et de riches citoyens 